\title{
Predecessors catalans i continuadors europeus del cant V de l'Orlando Furioso
}

Antoni M. Espadaler

Antoni Bastero a la famosa Crusca provenzale, publicada a Roma el 1724, arrodoneix el seu comentari sobre el Tirant lo Blanc amb aquestes paraules: "Questo libro, per quel che appartiene a purità, ed eloquenza di lingua, debbe avvere il primo luogo tra i nostri Prosatori, ne più, ne meno, come il Decamerone fra i Toscani». Aquesta és l'opinió que preval, com ha mostrat Vicent Martines, a les anotacions de bibliòfils i curiosos de la Itàlia del segle XVIII. Ara bé, és fora de tot dubte que Bastero ofereix una consideració positiva de l'estil de Martorell força sorprenent, ja que si alguna cosa no ha estat mai lloada en el Tirant ha estat justament l'estil, que entraria sense gaire esforç en les "necedades de industria" que va cometre el seu autor, segons Cervantes, $\mathrm{i}$ que li valgueren que Pedro Pérez el condemnés a «galeras por todos los dias de su vida».

No és tampoc aquest, d'altra banda, l'aspecte que va atreure el comte de Caylus a l'hora de traduir-lo, cap als anys trenta del XVIII, al francès. Al comte, que manava un regiment a la Catalunya que lluitava contra els Borbons, li interessaven, pel que sembla, bàsicament dues coses: una ètica de coratge que s'expressava en els fets d'armes de Tirant, i els tripijocs amorosos. En aquest darrer aspecte, no està de més recordar dos detalls. En primer lloc, que la traducció francesa — segons m'informa Jordi Gàlvez, que s'està dedicant a aquests afers - al contrari de la castellana, que és més púdica que l'original, tendeix a fer un punt més explícit que el text de Martorell tot el que són insinuacions més o menys atrevides. I en segon lloc, i reforçant-ho, és bo de consignar que la quarta edició, publicada prudentment —i falsa: el més probable és que es fes a París, en una impremta especialitzada- a Amsterdam per mor de la censura, anava acompanyada d'uns gravats que il.lustraven els moments i les actituds més entremaliades de la novel.la. Amb la qual cosa anem a parar al segon sentit —el més popular- d'allò que suscita el simple esment del Decameron, o sia no en el sentit de model de prosa que li dóna Bastero, sinó en el que li dóna Joan Fuster quan afirma que «El Tirant traspua una certa energia boccacciana». La mateixa que devia trobar-hi l'emperadriu Caterina de Rússia, l'anomenada Messalina del Nord, que confessa a les seves Memòries que el primer llibre que aconseguí de llegir sencer fou el Tirant, i que s'extasiava davant d'una escena, com a mínim, càlidament ambigua: la de la donzella de pell tan blanca que quan 
bevia vi vermell se li veia baixar per la gola. Imatge que, per cert, Francesc Fontanella aplicà a Venus a Lo desengany, i Miquel dels Sants Olivers, llevant-li tota picardia, a L'hereva de Provença.

Tanmateix, com és sabut $\mathrm{i}$ ha estat exposat per Francisco Rico, la primera recepció indígena, genuïnament valenciana del Tirant no anava precisament per aquest camí. Recordem, però, que segons el colofó, l'obra s'estampa «a pregàries de la noble dona Isabel de Lloris», i, en efecte, són dones les que apreixen a Lo somni de Joan Joan de Jaume Gassull, de 1497, debatent entre elles, amb el Tirant com a autoritat:

\author{
Digau, Senyora: \\ ¿vós, que sou gran oradora \\ e gran legista, \\ que al.legau tant lo Salmista \\ i lo Tirant \\ (perquè esta $\mathrm{i}$ jo estam altercant) \\ digau-nos com \\ lo déu d'Amor ha nom de nom?
}

El debat entre aquestes dames tocades d'humanisme —orador, aclara Rico, és el mot que designa l'humanista - i que barregen el sacre i el profa, es complementa amb l'esment a Joan Roís de Corella com a deu d'on mana tot aquest saber. Aquests versos assenyalen una utilització del Tirant en polèmica al voltant del debat sobre l'amor. És, doncs, una utilització, tot i que distesa, prou seriosa i elevada del text, al marge de les opinions que hem vist, o de l'elogi del realisme i de les aventures amoroses en els diversos graus i personatges que interessaren tant Cervantes. Les dames valencianes, de fet, recorren al Tirant continuant una dinàmica que Martorell ja havia previst: la disputa, plena de regust escolar i no exempta de pedanteria, entre dues dones amb recurs a un tercer que fa de jutge i la resol. Tant al Tirant com al Somni les dames desenrotllen una qüestió, amb la qual cosa tornem a ser a Boccaccio, perquè crec que no hi pot haver dubtes que en aquest punt precís el Tirant depèn del Filocolo, i de les conegudes «Quistioni d'amore» del llibre quart.

Si a València - almenys breument, cal dir-ho, car a partir del 1500 desapareix tota menció a la novel.la en català, mentre a la ciutat se salden els exemplars que havien quedat sense vendre de la primera edició de 715s'imposa com a llibre del qual extreure un aprenentatge d'amor, i entre un públic femení, ¿`com el reberen els italians?

L'arribada del Tirant a Itàlia és estrictament contemporània a la seva sortida al mercat valencià. El seu editor, l'alemany Joan Rix de Cura — ho ha remarcat darrerament Joan Perera - abans de treballar al Regne de València ho havia fet a Alemanya i a Itàlia, on mantenia importants contactes. Tant és així que al costat dels exemplars que constituïen l'edició majoritària, caracteritzada en el seu segon plec per una orla magnífica, en reservà d'altres per lliu- 
rar a diversos personantges amb qui havia estat relacionat. Això explica que hi hagi exemplars del Tirant sense orla a la portada, ja que Rix de Cura els reservava per ornamentar-los en funció del destinatari. Es tracta d'una tècnica habitual en els primers temps de la impremta, basada en la tradició de les miniatures, ja que persistia el desig d'embellir així els llibres. Un d'aquests exemplars "personalitzats» ho fou, probablement des de València mateix, amb les armes dels Gonzaga i dels Fieschi. El Tirant, d'altra banda, va ser llegit a la cort dels marquesos de Màntua, on va rebre l'impuls decisiu que el va dur fins a l'Orlando. La persona que sembla tenir-hi un paper clau és Isabella d'Este, la qual en deuria ser una fan, car a l'inventari dels seus béns fet amb motiu de la seva mort l'any 1539 apareixen dos Tirants, un de català i un de castellà. (Traduït per l'impressor Diego de Gumiel, responsable de l'edició barcelonina del 1497, i editat a Valladolid el 1511). A Isabella d'Este, de fet, s'atribueix el desig de posseir-ne una versió italiana que encomenà a Niccolò da Correggio. Aquesta versió, però, per bé que és segur que va projectar-se i més que probable que s'iniciés, mai no va arribar a fer-se del tot, i hom dóna per bona la suposició que l'abast de l'empresa devia superar àmpliament la bona voluntat de Niccolò da Correggio.

L'interès per l'obra no devia estingir-se a la cort de Ferrara, així com tampoc les ganes d'Isabella d'Este de voler acabar d'entendre del tot una novel.la escrita en una llengua que sens dubte intuïa però que no dominava, perquè encarregà la feina de traduir-lo a un matemàtic i astròleg de la seva cort anomenat Bartolomeo Manfredi. Aquest mantovà havia escrit ja una comèdia en «Terza rima» dita Paraclito, una comèdia en prosa titulada Filadelfia i havia demostrat les seves qualitats com a traductor portant a l'italià el 1513 la Cárcel de amor de Diego de San Pedro. La feina, segons es desprèn d'una lletra de Manfredi de març de l'any 1518 ja era acabada en aquells dies, però el llibre encara no era en condicions de ser lliurat a Frederic de Mantova, fill d'Isabella. Això s'acomplí el 1519. De la seva importància, de l'interès que havia suscitat, de la vàlua del treball de Manfredi en dóna compte aquesta estrofa de Cessio de Narni al poema La morte del danese, de 1521:

Lelio due libri, uno per man, tendeva da lui tradutti ne la lingua toscha: l'un Carcere d'amor chiamar faceva, l'altro Tirante, ognun credo el conoscha.

Questo a Fedrico Marchese leggeva, che in lingua externa prima obscura e foscha visto l'havea, et per tal exercitio l'havea premiato di bon benefitio.

Aquests versos testimonien sense febleses l'èxit del Tirant a la cort de Ferrara -ognun credo el conosca - així com la fama i el guany — que tot comptaque li significaren a Manfredi per part del marquès i el seu públic. L'obra, tanmateix, no va ser impresa fins al 1538 a Venècia, i se'n van fer dues edicions 
més, amb les inevitables variants, el 1566 i el 1611. És pràcticament segur que el comte de Caylus va fer la seva versió, més reduïda, sobre la italiana.

Pel que fa a la traducció, val la pena d'escoltar el que en diu Giuseppe Sansone en el pròleg a la versió italitana: «La traduzione del romanzo catalano allestita da Lelio Manfredi può definirsi senz'altro un'operazione di notevole livello sia in ordine alla qualità sia in rapporto allà fedeltà e, complessivamente, di ben maggiore riuscita e aderenza al dettato originale che non quella castigliana del 1511. Ma, per fedele che una traduzione possa essere, interventi di diversa entità, transgressioni di non grande momento e soluzioni divesificate sono pur sempre inevitabili» El mateix Sansone ha posat en relleu la capacitat de penetració del traductor italià, especialment apreciable en el moment de traduir els versos de l'obra. Així, per exemple, al cap 125, Tirant fa preparar unes banderes: «E l'una féu pintar, sobre camper verd, cadenats d'or d'aquest llong que tanquen les portes; e era plena, tota la bandera, d'aquells cadanats, e deia lo mot:

La lletra que està primera

en lo nom d'esta pintura

és la clau $a b$ què ventura

tancada té la darrera.

La quarteta amaga un enigma força senzill: la primera lletra de la paraula cadenat és la $c$, la inicial de Carmesina, i la darrera, la $t$, la de Tirant. El traductor castellà interpreta a la lletra però en haver convertit el cadenat en calnados, es perd tota referència a la lletra inicial del nom del protagonista masculí de la novel.la, i per tant es fa del tot incomprensible el joc que proposa Martorell. Manfredi, en canvi, opta per una lleugera llibertat literal que li permet una plena adhesió al sentit de la matèria. I així escriu:

Questa lettera che ottiene prima il nome in la pittura, la chiave è con cui ventura l'ottava serrata tiene.

La referència és a chiavistegli, que reporta fidelment cadenats, la vuitena lletra de la qual és amb encert i precisió la inicial del nom Tirant.

La traducció italiana divideix el Tirant en 7 parts — cosa que l'original no fa- i conté dues dedicatòries, que són sens dubte una bona pista per copsar com els principals lectors reberen la novel.la. La primera, dedicada com també la segona a Frederic Gonzaga, és obra del seu editor, Federigo Torregiano, ja que Manfredi, seguint una mena de malfat que afectà a Martorell i a Galba, "preparandosi per istampare l'opra sua, fu intercetto da morte e cadde prima che potesse pervenire al segno ove havea il suo corso indirizzato».

Aquesta dedicatòria — com la segona - és en bona part un plagi del pròleg de Martorell al Tirant; i s'hi assegura que Manfredi féu la traducció "per 
ampliare la nobil arte di cavaleria e farla in Italia più celebre che prima». La segona, obra del mateix Manfredi, i on es plagia a pleret la dedicatòria de Martorell a Ferran de Portugal, que al seu temps és un plagi flagrant de la d'Enric de Villena als Dotze treballs d'Hèrcules, subratlla la utilitat cívicomilitar del llibre, afegint-hi, però, una nota que em sembla important i que de ben segur té a veure amb l'interès que provocava en la cort de Ferrara la literuatura cavalleresca, i amb la poderosa revifalla que sota l'estímul dels marquesos es produeix.

Manfredi diu que els fets heroics de tants cavallers del passat són completament desconeguts a Itàlia. Una Itàlia, d'altra banda, «parvenuta — des de Constantí, car sota la pressió dels bàrbars ha quedat al marge d'aquest saber- alla quasi estrema roina et distruttione». Així, les gestes i els noms que són coneguts dels altres pobles «a noi era ignoti e occulti», «e per questo vostra celsitudine, non tanto d'arme quanto di lettre dotata e decorata, sforzandosi di ridurre l'Italia a quel sublime grado che già, se non d'arme e di scettro, almeno di lettre fu, si dignò di eshortarmi che diffusamente descrivere io gli solessi acciò che gli animosi cuori, per gli eccellenti essempi di quelli mossi et incitati da vertuosa invidia, ad alte e magnanime imprese si accingessero".

L'èmfasi, com es veu, es posa en l'heroicitat que prové no de la milícia i la seva pràctica, sinó de la literatura, és a dir que en insistir en la virtut i assenyalar-ne el camp de la lletra, Manfredi li atorga un valor sobretot moral, que d'altra banda no hem de considerar gaire allunyat del que pretenia Martorell. Ara bé, convé no oblidar que Martorell no només perseguia la difusió d'aliment per a la virtut heroica, sinó també que «la nació d'on jo só natural se'n puxa alegrar», o sia que al costat d'un ben acceptable profit hi hagi també una plausible distracció, sense preocupar-se gaire, a més a més, per a desesperació de Cervantes, que hi hagués cap mena de connexió entre una intencionalitat i l'altra.

I a mi em fa tot l'efecte que això, val a dir l'energia boccacciana que procura alegria i que ara ens reapareix, i que en el pròleg italià no s'esmenta, és el que interessà més a Itàlia, si considerem l'empremta del Tirant en la seva literatura, representada, com ja sabem, per l'Orlando furioso.

Segons va explicar Pio Rajna a Le fonti dell'Orlando furioso el Tirant seria la font del truculent episodi que té lloc al cant V. Episodi que em permeto reduir breument a memòria.

La donzella Dalinda explica que trobant-se al servei de Ginevra, s'havia enamorat de Polinesso, el qual amb una escala de corda s'enfilava a la cambra de la mateixa Ginevra on era rebut $i$ adequadament atès per Dalinda, tot $i$ que, segons aquesta «fingeva molto e amava poco». Però heus ací que de cop i volta «si mostrò nuovo amante/della bella Ginevra», i per tal d'aconseguir-la demana a Dalinda que l'ajudi, ja que sempre serà el seu amant. Ella accepta. A tot això, arriba d'Itàlia a Escòcia un jove cavaller de nom Ariodante, "grato al re, più grato era alla figlia», i la flama de l'amor llur esdevé tan potent que supera el Vesuvi i l'Etna. Polinesso, en conseqüència, és rebutjat, i, en «vedersi un altro preferito/come superbo, cosí mal sofferse,/che tutto in ira e 
in odio si converse». De manera que pensa venjar-se, sembrant discòrdia entre Ginevra i Ariodante, col.locant Ginevra «in ignomia immensa». O sia, atès el codi d'honor implícit a l'obra, anul-lar-la, exterminar-la, llevant-li tot honor per tal que ja no pugui ser aceptada per cap home. Per infamar-la demana a Dalinda que "come ella s'orna e come il crin dispone/studia imitarla e cerca il più che sai/di parer dessa». Ell, mentre ella es prepara per assemblar-se a la filla del rei, explica a Ariodante que Ginevra és la seva amiga, i que fa amb ella allò que Ariodante de ben segur desitja però que la cortesia li prohibeix de fer i ni tan sols sol-licitar, sinó a través d'un llenguatge i una conducta alambinats i metaforics. Així, amb una passió numèrica que sembla preludiar el Don Giovanni de Da Ponte i Mozart, diu:

Non passa mese che tre, quattro e sei

e talor dieci notti io non mi truovi

nudo abbracciato in quel piacer con lei,

ch'all'amoroso ardor par che sì giovi

I per fer-li-ho clar li proposa que s'amagui entre unes cases abandonades, des d'on podrà veure com ell és rebut amb besos ardents i abraçades acollidores per Ginevra. Ginevra, naturalment, no és la Princesa sinó Dalinda, que la suplanta, vestida, pentinada i maquillada com ella. En veure-ho, Ariodante vol llevar-se la vida, cosa que impedeix el seu germà, que l'acompanyava, el qual acusa després Ginevra de deshonorar-lo. A la fi, a través d'una batalla judicial Palinesso mor a mans d'Ariodante, el qual prova de fet i per les armes la innocència de Ginevra.

La font, amb les naturals variants, d'aquest episodi, particularment de la trama que porta a la seva escena culminant és, sens dubte, el capítol 283 del Tirant: Ficció que féu la reprovada Viuda. La Viuda, en efecte, una dona malalta, devorada per una sexualitat insatisfeta, vol atreure's Tirant, i per a això ordeix un pla per infamar Carmesina. Disposa així en una vella casa un llit molt ben parat, i un joc de miralls a través dels quals Tirant podrà accedir, ja que la finestra és molt alta, a contemplar el que s'esdevé a l'exterior. A fora, al jardí, Plaerdemavida, seguint el pla de la Viuda, es disfressa d'hortolà Lauseta, negre moro, esclau "comprat e venut», i com a tal juga amb Carmesina, i en aquests termes: «se acostà envers la princessa e asigué's al seu costat, e pres-li les mans e besà-les-hi. Aprés li posà les mans als pits e tocà-li les mamelles, e feya-li requestes d'amor. E la princessa feia grans rialles. Aprés ell se acostà tant e posà-li les mans dejús les faldes, ab gran alegria que totes estaven de les coses plasents que Plaerdemavida deya».

Tirant en veure-ho, tement que els miralls no li falsifiquessin la realitat, els trenca, «mirant dins si havia alguna cosa maliciosa que fos feta per art de nigromància, e no trobà res del que pensava». Llavors ha d'enfilar-se amb una corda passada a través d'una biga, i en posició més aviat ridícula seguir contemplant tan dolorosa escena, o sia com un esclau negre fa el que hem descrit amb Carmesina. 
La resta és coneguda. La Viuda tempta Tirant, el qual cau en una profunda depressió, mata ple d'ira el pobre Lauseta, i torna, en una fugida, cap al camp de batalla. Quan Plaerdemavida li explica ja dalt de la nau la veritat, una tempesta els porta Barberia on naufraga $i$ on comencen els set anys de l'aventura africana.

Ariosto, com s'ha vist, hi introdueix canvis força notables. El paper de la Viuda l'adopta un home que té més aviat trets de don Juan, Polinesso. La implicada, Ginevra, no intervé, i l'auxiliar necessària ocupa no el lloc d'un home de baixa condició sinó el lloc mateix de la Princesa, mentre Dalinda accepta, en principi sorprenentment, i tot i no fiar-se del seu amant, de suplantar-la.

El lloc d'observació d'Ariodante és similar, però menys espectacular que el de Tirant, i, cosa que em sembla remarcable, la seva reacció també és molt diferent. Ariodante, en efecte, pensa a matar-se com a amant traït. Tirant, en canvi, no pensa pas en això ni, cosa que sorprèn més, a prendre venjança sobre ella, sinó només sobre el negre. La cosa podria explicar-se perquè Tirant en aquest moment de la novel.la és un personatge insatisfet —amb alguna cosa d'indefinible, vull dir no explícita ni mai explicitada a la novel.la, que el neguiteja-, bloquejat, i que només tornarà a dominar la situació i la seva personalitat tornarà a mostrar-se sòlida després dels set anys de purgació a Àfrica.

L'escena escandalitzà Raina, i encara ara els erudits hi passen de puntetes, car és evident que en ser una representació que varia de matís segons el punt de vista - i n'hi ha gairebé tants com personantges - no escapa a ningú que mentre Tirant creu veure un incomprensible joc pujat de to entre un esclau i una princesa, la princesa no veu altra cosa que la continuació dels jocs sense fronteres — vull dir amb accès a llocs que a Tirant són vedats - entre ella i Plaerdemavida. Jocs tan agosarats que la Princesa en una ocasió arriba a alarmar-se en creure que la donzella era "temptada d'anar contra la sua natura».

A l'Orlando aquesta complexitat sexual s'esvaeix. Almenys aparentment. I guanya més importància el que fa referència a l'honor masculí perdut, vinculat a la conducta eròtica de les dones, que és una preocupació dels temps, o almenys des que s'imposà un model de dona sotmesa en tot al poder masculí, i que Boccaccio plasmà tan bé en la història de Valter i Griselda. Ara, Raina culpava el Tirant d'un fet que li semblava incomportable, com era que Dalinda accedís a ocupar el lloc de Ginevra, estant enamorada de Polinesso: "Che costei sia disposta a favorire le nozze dell'amante colla principessa, sta bene; accade a molti di sposare una donna e di amar-ne un'altra; ma ciò che Polinesso le chiede, non può essere consentito dall'amor proprio di nessuna femmina».

Paolo Valesio, en un article ple de malícia, ha analitzat a la manera d'Orlando (Francesco), els tres textos — el Tirant, el d'Ariosto i el de Rajnai arriba a la conclusió que no és cert que a l'Orlando l'escena s'hagi desvinculat del tot de l'original i que, per tant, les incompresions de Raina no són 
acceptables. Des del seu punt de vista, la suplantació és una forma de possessió. I d'aquesta manera, acceptant de fer-se passar per l'altra

ne dissimile essendo anch'io d'aspetto ne di persona de Ginevra molto

segons la seva pròpia opinió, no només satisfeia els seus desitjos eròtico-sentimentals «normals» en relació a Polinesso, sinó que també alliberava, ocupant el seu lloc, els seus impulsos homosexuals en fondre en un sol espai el que abans, al Tirant, era ocupat per dues dones: Carmesina i Plaerdemavida.

L'escena, en qualsevol cas, és densa i rica de significacions i possibilitats. Per tant, no és d'estranyar que hagi tingut una important repercussió literària. L'esquema que proporciona el nucli format per un home jove i poderós que necessita reafirmar el seu estatus a través de l'obtenció de diverses dones, i que quan no pot aconseguir aquella que l'obsesiona, decideix d'infamar-la, trobant-hi al damunt un plaer — che d'infamar Ginevra era sì lieto-, és precisament la base de l'obra de Juan de Cueva El infamador, de 1581, que és, com se sap, un dels precedents clars del Burlador de Sevilla de Tirso de Molina.

L'escena estricta serà represa per Jerónimo de Huerta en un poema cavalleresc titulat Florando de Castilla, lauro de caballeros, de 1588. Ací Polinesso es diu Clarinarte i Dalinda Safira, amb un final més en clau de comèdia, com diu Chevalier, car els còmplices acaben casant-se.

On, però, la repercussió fou més directa, fou a la mateixa Itàlia. El 1554 es publicaven a Lucca Le novelle de Matteo Bandello. La novel.la XXII de la primera part reprenia el tema de la suplantació de la personalitat de la donzella, i en feia una narració força àgil en la qual intervenia el rei Pere el Gran: «Narra il signor Scipione Attellano come il signor Timbreo de Cardena essendo col re Piero di Ragona in Messina s'innamora di Fenicia Lionata, e i varii e fortunevoli accidenti che avveneero prima che per moglie la prendesse». Timbreo de Cardona, arribat a Sicília poc després de les Vespres Sicilianes en el seguici del rei Pere, s'enamora d'una jove anomenada Fenicia, i quan, amb el consentiment patern són a punt de casar-se intervé per impedir-ho un tal Girondo Olerio Valenziano, dient a Timbreo que Fenicia té un amant. Per convèncer-lo, li ho demostra amb el mateix recurs que Polinesso: una donzella convenientment ensinistrada atén amablement Girondo, i Timbreo entén que es tracta de l'amant de Fenicia. Això ho comunica el dolgut Timbreo als seus pares desfent el compromís. La noia experimenta un shock tan fort que els metges la prenen per morta, però quan es disposen a enterrar-la s'adonen que encara és viva, i, per protegir-la del deshonor la duen al camp perquè es refaci, mentre la gent de Messina encara la té per morta. Amb el temps, Timbreo confessa la seva difamació, penedit de la mort de la noia, i amb Timbreo visiten el pare de Fenicia, que es diu Lionato. Aquest com a reparació exigeix que Timbreo no es casi fins que ell no li proporcioni la dona que li convingui. Aquesta serà Fenicia, que ha guanyat tanta salut que no la reconeix fins que són 
casats. La parella va aleshores a la cort d'Aragó on explica la seva història i on són esplèndidament tractats.

El 1569 les novel.les de Bandello apareixen en francès dintre de les Histoires tragiques de François de Belleforest, i la que acabo de resumir rep el títol de "Comment Timbrée de Cardone devint amoureux à Messine, de Fénicie Leonati et les divers et étranges accidents qui advinrent avant qu'il l'épousât». Doncs bé, aquesta narració en francès és una de les fonts reconegudes, juntament amb el mateix Orlando, traduït a l'anglès per sir John Harington el 1591, de l'obra de Shakespeare Much ado about nothing, escrita entre l'estiu de $1598 \mathrm{i}$ la primavera de 1599. Aquí l'envejós serà don John, germà bastard del Príncep don Pedro d'Aragó; Timbreo es diu Claudio, i Fenicia Hero. Els recursos són idèntics, només que ara la núvia és acusada en el moment mateix de la cerimònia, i la veritat es descobreix perquè casualment uns agutzils sorprenen una conversa entre companys de don John que els permet de saber la veritat. Aclarit l'engany, Claudio es posa a disposició dels pares d'ella, a qui creu morta i ells li imposen la condició de casar-se amb una neboda seva, en la qual, un cop casats, en descobrir el rostre, reconeix a la mateixa Hero.

Ara bé, aquesta llarga i magnífica excursió literària té, amb anterioritat al Tirant, una història no menys atractiva. El passatge de les maquinacions de la Viuda Reposada, que té un regust teatral tan fort que ha estat qualificat per Grilli com l'entremès del negre Lauseta, i que en conjunt té un fort caire d'originalitat, en realitat ve emmarcat per un altre text que li serveix de fonament fins i tot a nivell textual, com ha demostrat no fa gaire Carles Garriga. En efecte, darrera aquest fragment hi ha, com havia insinuat Francisco Rico a la Primera cuarentena, la Tragèdia de Caldesa de Joan Roís de Corella. Els elements de connexió no són tant d'ordre escenogràfic, com de sentit de la mateixa posta en escena. La Tragèdia narra en primera persona com un amant descobreix que és traït per una dama a la qual estimava de la manera més alambinada possible, mentre ella, en canvi, es lliurava sense gaire manies a un home d'inferior condició. Això representa per a l'amant diguem-ne cortès, aquel que diu jo en en qualsevol cas, una humiliació irreparable, una derrota de proporcions gegantines. Les paraules que Tirant fa servir per expressar el seu estat d'ànim en veure exactament el mateix, o sia que la Princesa dóna a un negre de «cos lleig e diforme» com l'antiamant de Corella, el que a ell se li nega, són les mateixes que Corella usa per expressar la seva desolació.

La història pot tenir diverses fonts, Rico ha suggerit - Hauf hi ha posat pegues - que clericals, però el fet cert és que a la València del segle XV Martorell i Corella no foren els únics que imaginaren la posició d'un amant rigorós i de tota noblesa derrotat per algú de més baixa condició. Aquest és, en efecte, el tema central de la majoria dels poemes que porten el senyal "O foll Amor» en l'obra d'Ausiàs March, on s'explica el col-lapse de magnituds còsmiques experimentat per un amant com ell que cercava la unió més enllà de l'intel-lecte, i que ha estat vençut per l'home pec, és a dir per qui no cerca altra cosa que l'amor carnal. 
Deixant de banda el fet, per a mi enormement significatiu i pel que fa a Corella intel.ligentíssim de treure el màxim de profit a March en prosa, arribem al punt de partida d'un viatge literari per gairebé tot Europa. March doncs seria l'inici d'un recorregut que passaria per Corella, es desenrotllaria al Tirant, prendria un nou caire al'Orlando, d'on surtiria un ramal que conduiria al teatre i l'èpica espanyols dels segles XVI i XVII, i un altre més vinculat a les seves implicacions originàries que trobaria en Bandello el seu punt d'enllaç fins a desembocar en Shakespeare. Un trajecte que posaria els nostres textos en la primera línia de la cultura europea. 